\title{
Los derechos digitales durante la pandemia COVID-19 en Argentina, Brasil y México
}

\section{Digital rights during COVID-19 pandemic in Argentina, Brazil and Mexico}

\author{
Bizberge, A. y Segura, M. S. ${ }^{1}$ \\ Recibido: 14-05-2020 - Aceptado: 10-08-2020 \\ https://doi.org/10.26441/RC19.2-2020-A4
}

RESUMEN: Este artículo estudia estrategias, actores, condiciones y debates sobre los derechos digitales durante la pandemia de COVID-19 en México, Argentina y Brasil. El abordaje teórico es el de la comunicación como un derecho humano fundamental y las políticas de la comunicación. El enfoque metodológico es un análisis comparativo teórico-normativo y socio-político. Los ejes de debate giraron en torno a los derechos digitales de acceso, privacidad y libertad de expresión. Las políticas estatales variaron en función de la orientación política de sus gobernantes, el enfoque de políticas públicas pre-existentes y las adoptadas frente a la COVID-19, y las relaciones de fuerza existentes entre los actores involucrados en cada país. Las empresas desarrollaron estrategias regresivas de las que, en ciertos casos, tuvieron que dar marcha atrás, y algunas progresivas pero excepcionales; la sociedad civil y los organismos internacionales impulsaron soluciones progresivas y de largo plazo.

Palabras clave: derechos digitales; internet; COVID-19; aislamiento; Latinoamérica.

\begin{abstract}
This article studies strategies, players, conditions and debates on digital rights during the COVID-19 pandemic in Mexico, Argentina and Brazil. The theoretical approach comes from the studies of communication as a fundamental human right and communication's policies. The methodological approach proposes a comparative theoretical-normative and socio-political analysis. The lines of debate were the digital rights of access, privacy and freedom of expression. State policies varied depending on the political orientation of their authorities, pre-existing public policies, the specific policies adopted against COVID-19, and the competing forces of the players involved in each country. The companies developed regressive strategies from which, in certain cases, they had to reverse, also implemented some progressive but exceptional measures; while civil society and international organizations promoted progressive and long-term solutions.
\end{abstract}

Keywords: digital rights; internet; COVID-19; lockdown; Latin America.

\footnotetext{
${ }^{1}$ Ana Bizberge es Doctora en Ciencias Sociales por la Universidad de Buenos Aires, Directora de la Maestría en Industrias Culturales de la Universidad Nacional de Quilmes y docente de la Facultad de Ciencias Sociales-Instituto de Estudios de América Latina y El Caribe de la Universidad de Buenos Aires. anabizberge@gmail.com, https:// orcid.org/0000-0001-8267-4700

María Soledad Segura es Doctora en Ciencias Sociales por la Universidad de Buenos Aires, Magister en Comunicación y Cultura por la Universidad Nacional de Córdoba, Profesora en las Facultades de Ciencias Sociales y Ciencias de la Comunicación de la misma universidad e Investigadora del Consejo Nacional de Investigaciones Científicas y Ténicas (CONICET). maria.soledad.segura@gmail.com, https://orcid.org/0000-0003-1847-942X
} 


\section{Introducción}

Las nuevas necesidades y problemas que se presentan durante el avance de la primera pandemia global de coronavirus (COVID-19) y las excepcionales medidas de aislamiento de la población adoptadas en un tercio de los países del mundo hicieron resurgir los debates públicos sobre los derechos digitales. Además, pasaron del estrecho círculo de especialistas a ser parte de la discusión social, mediática y política. Si bien los nuevos desafíos son internacionales por el alcance de la circulación del virus y las políticas adoptadas para enfrentarlo, así como por la estructura mundial de la red de internet y el carácter transnacional de las empresas proveedoras del servicio, en cada región y país adquieren particularidades específicas.

En este artículo se estudian estrategias, actores, condiciones, debates y disputas sobre los derechos digitales durante el avance de la pandemia y las diversas medidas de aislamiento dictadas en México, Argentina y Brasil. El interrogante central es el siguiente: ¿Qué derechos digitales se ven afectados por acción de las empresas y los gobiernos durante los confinamientos dispuestos con diversos niveles de restricción en todos los países de América Latina (excepto Nicaragua) desde el 13 de marzo -cuando lo estableció Uruguay, el primer país de la región en hacerlo- hasta el 13 de mayo -momento de cierre de la escritura de este artículo-; cómo se posicionan las organizaciones de la sociedad civil y los organismos internacionales; y qué precedentes sientan para el escenario post-crisis estas estrategias desarrolladas en un contexto de excepción?

Se aborda esta pregunta desde la perspectiva teórica de la comunicación como un derecho humano fundamental, así como desde el enfoque de las políticas de comunicación como terreno de disputa de sentidos en el marco de cierta configuración de las relaciones de fuerzas sociales. El enfoque metodológico es un análisis comparativo en dos niveles: uno teórico-normativo sobre la progresión o regresión de las medidas adoptadas en términos de derechos humanos; y otro socio-político que, en base a las pujas de poder existentes, analiza en qué medida en cada país es posible o no desarrollar políticas progresivas.

Se sostiene como argumento que los ejes de debate sobre internet durante la pandemia y el aislamiento en América Latina giran en torno a tres tipos de derechos digitales: acceso, privacidad y libertad de expresión. Cada uno de estos derechos se ve afectado por varias clases de problemas ocasionados por los gobiernos y/o por las empresas de internet: de conectividad, contenidos críticos pagos, geolocalización de pacientes, censura, promoción de la autocensura, desinformación. Las políticas estatales incluyeron algunas medidas regresivas y otras progresivas a veces en asociación con la sociedad civil: las diferencias entre los países se vinculan con la orientación política del gobernante, con el enfoque del conjunto de políticas públicas con las que se enfrentó el avance de la COVID-19, y con las diferentes relaciones de fuerza existentes entre los actores involucrados. Las empresas desarrollaron a nivel global estrategias regresivas de las que, en ciertos casos, tuvieron que dar marcha atrás, y algunas progresivas pero excepcionales; mientras que la sociedad civil de cada país y los organismos internacionales impulsaron soluciones progresivas y de largo plazo.

En primer lugar, se presenta el enfoque teórico-metodológico con el que se abordará el problema. Luego, se analizan comparativamente las estrategias y disputas desarrolladas en torno a los derechos digitales a la libertad de expresión, al acceso y a la privacidad en cada país analizado. En tercer lugar, se caracterizan a los principales actores en juego: empresas, gobiernos y sociedad civil nacional, y al estado de las relaciones de fuerza en la coyuntura estudiada. Finalmente, se ofrecen conclusiones.

\section{Enfoque teórico - metodológico}

Para dar cuenta del proceso de elaboración e implementación de políticas en el contexto de emergencia sanitaria, se entiende por política pública, la respuesta del Estado- por acción u omi- 
sión- frente a un problema que toma dimensión pública (Oszlak y O'Donnell, 1981). Implica, por lo tanto, pujas de sentidos en el marco de determinada configuración de las relaciones de poder (Castells, 2009). En particular, las políticas de comunicación refieren al establecimiento de metas generales para la organización del sistema de medios a través de la regulación (formal, como leyes o actos administrativos, o informal, como acuerdos voluntarios), que se elabora a partir de la interacción de distintos tipos de actores, que utilizan mecanismos formales e informales para incidir en la configuración del sector (Freedman, 2008 y McQuail, 2010). Con respecto a Internet, cada vez más se habla de "gobernanza" más que de políticas, para dar cuenta de un cambio en el proceso decisorio: del pasaje del clásico proceso de decisión que pone al Estado como actor central, hacia nuevas formas de estructura regulatoria y no jerárquica, donde los actores involucrados se sientan en la mesa de decisión como interesados con la misma legitimidad que otros actores y asumen el rol de reguladores junto con regulados (Rossi y Meier, 2012: 389; Iosifidis, 2011).

De este modo, para el estudio de las políticas que inciden en el ejercicio de derechos digitales no solo es importante analizar el comportamiento de los Estados de la región, sino también indagar sobre la discusión social de estos temas, el posicionamiento de las organizaciones de la sociedad civil y el accionar de las empresas, especialmente, los intermediarios de Internet como habilitadores u obturadores del ejercicio de derechos en línea.

La sociedad civil que procura incidir en la formulación de políticas públicas al tiempo que desarrolla sus propias políticas, no es un todo unificado, sino que es compleja, conflictiva y heterogénea. No se adscribe a la visión de una esfera homogénea ni pura, sede de la libertad frente a la opresión estatal, y del altruismo frente a la dominación del mercado. Por el contrario, se entiende que mantiene una relación de autonomía relativa con el Estado y el mercado (Sorj, 2010). En particular, el activismo por los derechos digitales es una forma de acción colectiva que promueve el acceso y la gestión más igualitarios de la tecnología y de los datos, se involucra con nuevas formas de producción de información y conocimiento, y cuestiona los conceptos dominantes sobre la digitalización de información y la conectividad (Milan y van der Velden, 2016).

En tanto, las grandes plataformas digitales contribuyen en la actualidad al surgimiento de nuevas formas de captura de las políticas públicas por parte de las elites (Schiffrin, 2017). Esto también fue reconocido por organismos internacionales con incidencia en el sistema latinoamericano: tomando como principio básico el derecho al acceso y uso de internet como un derecho humano (OEA, 2019; 2011), reconocen el potencial de Internet para la circulación de ideas pero, al mismo tiempo, alertan sobre los desafíos que generan los intermediarios de Internet, en la medida en que por su tamaño y posición ejercen un "control privado" para el acceso y la circulación de contenidos en la red (ONU, 2018; CIDH, 2013, 2017; OEA, 2019; UNESCO, 2019).

Los derechos digitales implican la protección y realización de derechos existentes como el derecho a la privacidad, al acceso a la información, o a la libertad de expresión en el contexto de las nuevas tecnologías digitales y de conectividad. Son los de acceder, usar, crear y publicar por medios digitales así como acceder y utilizar dispositivos electrónicos y redes de telecomunicaciones. En particular, los derechos a la libertad de expresión y el acceso a la información en internet retoman la tradición del derecho humano a la comunicación basado en los principios de acceso, pluralidad, diversidad, participación, y equidad (MacBride, 1980), referidos tanto al acceso y uso de las tecnologías de la digitalización y la conectividad mismas, como a la producción, acceso y gestión de datos privados y públicos. El derecho a la comunicación es un derecho que incluye y supera los de libertad de expresión (no censura ni inducción a la autocensura) y acceso a la información pública. Al aplicarse a nuevas tecnologías, enfrentan nuevos desafíos que obligan a redefiniciones, precisiones y ampliaciones de estos derechos. Una de esas novedades 
es el principio de neutralidad de la red que establece que todos los contenidos que circulan por Internet deben recibir el mismo trato y no ser discriminados por su origen, uso o aplicación (ver $\mathrm{Wu}, 2003)$. Se promueve especialmente el libre acceso - con un reconocimiento de los derechos de autor compatible con el libre acceso- y la producción colaborativa que la tecnología permite (Katzenbach, 2012; Jenkins, 2006; Lessig, 2004). Se retoman también los derechos civiles a la privacidad frente al control de estados y el uso de datos privados con fines comerciales: la vigilancia digital se vincula con la utilización gratuita de los datos de comportamiento, en parte para mejorar productos o servicios, y otra parte para anticipar lo que haremos en el futuro (Zuboff, 2019).

A nivel metodológico, se realiza un análisis comparativo de los derechos digitales afectados por gobiernos y empresas, y los posicionamientos de la sociedad civil durante el avance de la pandemia y las medidas de aislamiento adoptadas entre marzo y mayo de 2020 en Argentina, Brasil y México. Los criterios de selección de estos casos son los siguientes:

- Son los países que tienen mayor extensión territorial, mayor cantidad de habitantes (junto con Colombia), y mayor Producto Bruto Interno nominal de América Latina; por lo que su gravitación política y económica en la región es relevante (CEPAL, 2019).

- Sus gobiernos tienen diferentes orientaciones políticas: de derecha en Brasil y progresistas de partidos tradicionales en Argentina y México (CELAG, 2020).

- Las estrategias de comunicación política de sus gobiernos nacionales frente al avance de la pandemia fueron diferentes: en Argentina se asumió el problema rápidamente, en Brasil se lo niega, y en México inicialmente se minimizó el problema y luego se lo afrontó (CELAG, 2020.).

- Las medidas adoptadas para contener la transmisión viral tienen diversos niveles de restricción: son muy restrictivas con aislamiento obligatorio en todo el país en Argentina desde el 20 de marzo y medianamente restrictivas con confinamiento recomendado a nivel nacional y obligatorio sólo en algunos estados en Brasil y México desde el 17 y el 30 de marzo respectivamente (BBC News Mundo, 2020).

- Los estados desarrollaron estrategias diversas frente a las nuevas necesidades y problemas vinculados a derechos digitales que emergieron durante el avance de la pandemia.

El análisis comparativo se lleva a cabo en dos niveles. Por un lado, se realiza un abordaje teórico-normativo de las implicancias en términos de progresión o regresión de derechos de las políticas públicas y las estrategias empresariales adoptadas. Por otro lado, se hace un estudio socio-político del estado de las relaciones de fuerza entre los tres actores considerados en cada país que permite comprender en qué medida estas condiciones hacen posible o no desarrollar políticas progresivas. El estudio se basa en distintas fuentes como documentos públicos, normativas (resoluciones, decretos, etc), declaraciones y recomendaciones de organismos internacionales, artículos de prensa masiva y especializada.

\section{Estrategias y disputas}

En el contexto de la expansión de la pandemia de COVID-19, las discusiones públicas sobre derechos digitales en América Latina giraron en torno a libertad de expresión, acceso y privacidad. Frente al accionar de Estados y empresas, tanto organismos internacionales como organizaciones de la sociedad civil y academia de cada país emitieron alertas y recomendaciones específicas. 


\subsection{Libertad de expresión}

Con respecto a la libertad de expresión, se identificaron tres tipos de problemas: la propagación de desinformación por parte de empresas y gobiernos, la censura automática de las plataformas de redes sociales, y la promoción de la autocensura por los gobiernos.

Sobre la propagación de desinformación: El director general de la Organización Mundial de la Salud, Tedros Adhanom Ghebreyesus, advirtió sobre los riesgos de la "infodemia" -la propagación de desinformación sobre la pandemia-, y sostuvo que "la evolución del brote del coronavirus dependerá de la medida en que se haga llegar la información correcta a la gente que lo necesita" (Ghebreyesus, 2020). Los Relatores de Libertad de Expresión de ONU, OEA y OSCE, a través de una declaración conjunta y también separadamente, instaron a los gobiernos a promover y proteger el acceso y la libre circulación de la información durante la pandemia, y a proporcionar información veraz sobre la naturaleza de la amenaza que supone la COVID-19, y a las empresas de Internet que aborden el problema de la información falsa sobre la pandemia con información fiable (OEA, 2020; ONU, 2020). Para contribuir en este sentido, UNESCO creó un "Centro de recursos de respuestas a la COVID-19" que incluye materiales sobre desinformación; libertad de expresión, seguridad de los periodistas y derechos humanos interrelacionados; acceso a la información y al conocimiento; y tecnologías digitales. Además, elaboró declaraciones (por ejemplo, Comité Internacional de Bioética y Comisión Mundial de Ética del Conocimiento Científico y la Tecnología de la UNESCO, 2020) y documentos de política (como Possetti \& Bontcheva, 2020a y 2020b) que también abordan el uso de tecnologías digitales y la desinformación.

En la misma línea, la Comisión Interamericana de Derechos Humanos (CIDH, 2020) publicó recomendaciones a gobiernos y empresas para abordar la pandemia desde un enfoque de derechos humanos en materia de libertad de expresión en Internet y para combatir la desinformación, asegurar el acceso a la información pública, entre otras (Bizberge, 2020). La Organización Panamericana de la Salud también manifestó su preocupación y proveyó materiales para combatir la desinformación sobre el riesgo sanitario.

La desinformación, en tanto información falsa, engañosa o incomprobable que se distribuye deliberadamente para promover la ignorancia con determinados intereses (CIDH, 2019), es producida y puesta a circular por medios de comunicación de masas, periodistas y comunicadores, gobernantes y dirigentes políticos, líderes religiosos, intelectuales y otras personas con influencia en la opinión pública. La posibilidad de su fácil propagación reticular, descentrada, instantánea y masiva por redes sociales es especialmente problemática (Amnesty International-Argentina, 2018). Sobre el nuevo tipo de coronavirus se propagaron múltiples discursos pseudocientíficos o anti científicos, negacionistas y conspirativos tan diversos como los astrológicos, belicistas, veganos o místicos. Ejemplo de esto a nivel gubernamental fueron las manifestaciones del presidente brasileño Jair Bolsonaro quien el 24 de marzo definió a la enfermedad como "uma gripezinha ou resfriadinho" (BBC News Mundo, 2020b). Inicialmente, el presidente de México, Antonio Manuel López Obrador, también minimizaba la amenaza sanitaria y, como lo hizo el 22 de marzo, solicitaba a la gente que "no dejen de salir" y no tomen medidas "exageradas" (El Universal, 2020). Sin embargo, el gobierno federal mexicano luego cambió de posicionamiento a tono con las medidas que estaban adoptando ya algunas autoridades autonómicas y aconsejaban los especialistas como su Subsecretario de Prevención y Promoción de la Salud, Hugo López-Gatell. Así, López-Gatell lidera las conferencias de prensa diarias en las que provee profusa información precisa sobre la emergencia sanitaria, y que son transmitidas en cadena por todos los medios públicos federales y por medios sociales. 
Ante los reclamos por la propagación de desinformación que ponen en riesgo la salud de miles de personas en todo el mundo, las corporaciones de redes sociales se vieron obligadas a tomar medidas. Twitter modificó sus políticas de moderación de contenidos para borrar tuits que nieguen recomendaciones sanitarias o animen a usar tratamientos nocivos (El Diario, 2020). WhatsApp, por su parte, limitó las posibilidades de reenvío de mensajes a uno por vez, lo que, según informó la compañía, tuvo como resultado la reducción de un $70 \%$ en el reenvío de mensajes (La Voz del Interior, 2020).

Por su parte, más de 90 organizaciones sociales verificadoras de datos de todo el mundo trabajan desde enero de 2020 en un proyecto colaborativo coordinado por la International Fact-Checking Network (IFCN) para desmentir información errónea relacionada con el coronavirus. En América Latina, desde abril de ese año, 22 medios de esta región y de España se aliaron en la red Latam Chequea, un proyecto colaborativo para verificar información sobre el coronavirus y luchar contra la "infodemia" (Fundación Gabo, 2020). Además, en cada país, organizaciones locales de verificación de datos como la argentina Chequeado también ofrecen chequeos específicos de información sobre COVID-19.

A nivel gubernamental, la agencia estatal de noticias de la Argentina, Télam, puso en marcha la plataforma de chequeo de información Confiar "para enfrentar la información falsa sobre coronavirus". Constituye una experiencia inédita de una plataforma estatal de verificación del discurso público.

Sobre la censura privada: Durante la crisis sanitaria global, el uso de inteligencia artificial por parte de las redes sociales muestra una vez más las limitaciones para la libertad de expresión: ya se registra una gran cantidad de casos de remoción de contenidos por supuestas violaciones a sus políticas. Uno de los casos más resonantes fue el de los mensajes en Twitter del presidente brasileño, Jair Bolsonaro, en los que desafiaba las recomendaciones de la OMS sobre la propagación de COVID-19 y desincentivaba el aislamiento, que fueron censurados por la plataforma. Más allá del juicio de valor sobre el contenido, lo acontecido fue una muestra cabal sobre las prácticas poco transparentes para la moderación de contenidos.

Los Relatores de Libertad de Expresión advirtieron que esta censura automática y poco transparente "puede dar lugar a la limitación del acceso a información importante para la salud pública y sólo debe realizarse cuando se cumplan las normas de necesidad y proporcionalidad" (OEA, 2020) y el Relator de ONU planteó que las compañías deben evitar depender exclusivamente de la moderación automatizada (ONU, 2020). La CIDH (2020) también recomendó a las empresas garantizar el acceso a los contenidos y abstenerse de bloquear sitios de medios de comunicación, plataformas o cuentas particulares de Internet.

Organizaciones latinoamericanas como Intervozes de Brasil, Artículo 19 y R3D de México, ADC de Argentina, Datos Protegidos de Chile y la regional Derechos Digitales, entre otras, vienen demandando desde hace tiempo transparencia y rendición de cuentas de las plataformas a través de mecanismos regulatorios más o menos formales. Por eso, en este contexto, algunas de ellas como la regional OBSERVACOM y Fundación Karisma de Colombia (2020) lanzaron iniciativas para documentar casos de bloqueos, eliminaciones de contenidos o censuras de cualquier tipo en el marco del avance de la COVID-19.

Sobre la promoción gubernamental de la autocensura: El 8 de abril la ministra argentina de Seguridad, Sabina Frederic, anunció que, en el contexto de pandemia y aislamiento, estaban haciendo "ciberpatrullaje" de la información públicamente disponible en redes sociales para 
monitorear "el humor social", lo que desató una fuerte polémica. Además, se documentaron sólo durante el mes de abril al menos 5 detenciones de personas vinculadas con sus expresiones en redes sociales, originadas en esta práctica de inteligencia de fuente abierta. Como advirtieron numerosos expertos, organismos internacionales como la CIDH (2020b) y organizaciones cívicas como la Iniciativa ciudadana para el Control del Sistema de Inteligencia (ICCSI, 2020) conformada por el Centro de Estudios Legales y Sociales (CELS, 2020), Fundación Vía Libre y el Instituto Latinoamericano de Seguridad y Democracia, esto viola la presunción de inocencia, quebranta la expectativa de privacidad que tienen las conversaciones incluso en el espacio público, y convierte a las fuerzas de seguridad en veedoras del discurso público. Por lo tanto, atenta contra la libertad de expresión, promueve la autocensura, reduce la participación ciudadana y es un problema para la democracia.

Las iniciativas de verificación de datos de las organizaciones cívicas de la región y la de la agencia estatal de noticias de Argentina, junto con medidas adoptadas a nivel global por las plataformas de redes sociales para reducir los riesgos de propagación masiva de desinformación contribuyen al acceso a la información veraz sobre la COVID-19 y son, por ende, progresivas en materia de derechos humanos. En cambio, la difusión gubernamental de desinformación que se registra en Brasil e inicialmente se registró también en México, las medidas de promoción de la autocensura del gobierno argentino, y el uso "excesivo" de inteligencia artificial para la moderación de contenidos por parte de las plataformas a nivel global son regresivas.

\subsection{Acceso}

Durante la pandemia y las medidas de aislamiento social obligatorio o recomendado implementadas por los gobiernos, se pusieron de manifiesto dos tipos de problemas de acceso a la conectividad y a los contenidos, para los que se tomaron diversas medidas.

Acceso a la conectividad: En América Latina, como en gran parte de los países del mundo donde se tomaron medidas similares, debido al aislamiento social preventivo obligatorio o recomendado por todos los gobiernos, excepto por el de Nicaragua, se incrementó el uso de la red un $25 \%$ promedio en toda la región durante la primera semana (Bertollini, 2020) por clases virtuales, teletrabajo, comunicaciones personales y comercio on line. La migración masiva al teletrabajo desafió la capacidad de enrutadores Wi-Fi en los hogares, motivado por un aumento de trabajo en la nube (incremento del $80 \%$ del tráfico de subida) y las videoconferencias. Por ejemplo, en países como Chile y Ecuador, se verificó una disminución de velocidad de banda ancha fija ( $-3 \%$ y $-19,6 \%$ respectivamente), al mismo tiempo que el incremento de la latencia de la banda ancha en distintos países de la región como Brasil (11,7\%), Chile (19,0\%), Ecuador (11,8\%) y México (7,4\%) (Ookla/Speedtest citado en CAF, 2020: 6). Esto hizo sonar las alarmas por un potencial "colapso" de la red. Sin embargo, organizaciones y expertos locales y globales como Internet Society aseguraron que la infraestructura de Internet ya se adapta en condiciones normales a picos de demanda de tráfico (por ejemplo, en las fiestas de fin de año o en eventos de interés mundial como los Juegos Olímpicos), por lo que no habría nada que temer en la red principal.

De todos modos, los gobiernos de la región buscaron mitigar los efectos del incremento del tráfico a través de una serie de medidas que incluyeron la declaración de las telecomunicaciones, tecnologías de la información y comunicación (TIC) e incluso radiodifusión como servicios esenciales; prácticas de gestión de tráfico de video; y campañas dirigidas a los usuarios sobre uso responsable de las redes. 
En Argentina se declaró "servicio esencial” a la telefonía fija y móvil, internet y televisión por cable o satelital y se prohibió su suspensión o corte por mora o falta de pago durante 180 días. En México, también se determinó la continuidad del servicio de telecomunicaciones como parte de las medidas para prevenir y mitigar los riesgos de la pandemia (Acuerdo de la Secretaría de Salud, 2020), y el Instituto Federal de Telecomunicaciones (IFT) exhortó a autoridades federales, estatales y municipales a mantener la prestación efectiva de servicios de telecomunicaciones y radiodifusión (IFT, 2020). En Brasil, se estableció que los servicios de telecomunicaciones e Internet son esenciales y debe garantizarse su funcionamiento durante la pandemia (Decreto 10.282/2020). La Agência Nacional de Telecomunicações (ANATEL) firmó un compromiso con distintas empresas para "mantener Brasil Conectado", lo que incluye continuidad en los servicios, atención prioritaria a organismos de salud y seguridad pública y brindar información a la población, entre otros aspectos (ANATEL, 2020). Sin embargo, ni el gobierno ni ANATEL tomaron medidas para prohibir cortes de servicio impago y el Tribunal Regional Federal de la Región 3 determinó que sí es posible cortar el servicio por falta de pago (Valente, 2020; ANATEL, 2020b).

Otra medida adoptada en Argentina fue el acuerdo entre el Ente Nacional de Comunicaciones (ENACOM), la empresa estatal Arsat y los proveedores privados Claro, Datco, Movistar y Telecom para brindarse soporte cruzado frente a potenciales incrementos significativos en el tráfico en sus redes mayoristas. No obstante, las micro, pequeñas y medianas empresas (MiPy$\mathrm{Me}$ ) minoristas que dan servicios de conexión a los hogares en gran parte del país reconocieron sus dificultades para responder al aumento del tráfico debido a sus redes obsoletas y demandan al gobierno medidas paliativas.

En Argentina, además, se hicieron campañas dirigidas a los usuarios sobre el uso responsable de las redes. Asimismo, el regulador argentino, ENACOM, acordó con Netflix y Youtube bajar la calidad de sus videos en el país para evitar sobrecargar las redes. De modo similar, en Brasil, ANATEL recibió una carta de compromiso de radiodifusores y proveedores de servicios audiovisuales por Internet para implementar medidas técnicas voluntarias para minimizar el impacto en la red por el uso de los servicios digitales (ANATEL, 2020c).

Además, si bien al momento de cierre de este artículo no hay todavía decisiones oficiales, tanto en México como en Brasil, los reguladores analizan opciones para la asignación temporal, durante la pandemia, de espectro adicional para los operadores móviles. Esta es una demanda que, a nivel regional, promueve desde hace tiempo la asociación de empresas móviles GSMA (2020) y que se retomó para mitigar los efectos del incremento de tráfico.

En este escenario, las organizaciones que impulsan redes comunitarias de internet en zonas rurales o urbano marginales, como Altermundi y Atalaya Sur en Argentina, Redes por la Diversidad, la Equidad y la Sustentabilidad A.C. y Rizhomática en México, y Artículo 19 en Brasil, reposicionan su propuesta como una opción para extender la conectividad en zonas a donde no llegan los prestadores privados ni estatales, o a las que llegan pero lo hacen con baja calidad y/o altos precios (Roca, 2020). La Asociación para el Progreso de las Comunicaciones (APC, 2020) recomienda que, para responder a la pandemia, se necesitan políticas de "rápida mejora de las redes comunitarias". En Argentina, por ejemplo, Altermundi, que ya tiene un convenio de enlace gratuito punto a punto con el centro de operación de redes de la Universidad Nacional de Córdoba, en esta coyuntura, para optimizar la calidad del servicio, reiteró a la empresa provincial de energía su solicitud de establecer un enlace con su tendido de fibra óptica. 
Acceso gratuito a contenidos: Además se adoptaron medidas para promover el acceso gratuito a contenidos educativos, de información sobre salud, y entretenimiento. En Argentina las organizaciones estudiantiles solicitaron que las empresas de conectividad permitieran el acceso gratuito a todos los dominios .edu.ar. El Ministerio de Educación de la Nación y las universidades nacionales hicieron los acuerdos correspondientes con los proveedores privados: Claro, Movistar y Telefónica. Además, las universidades públicas ofrecieron Becas de Conectividad a sus estudiantes de menores recursos, que consistieron en montos de dinero para pagar datos móviles o comodato de dispositivos para acceder a ellos.

En México, los operadores móviles AT\&T, Telefónica, Telcel (América Móvil) y Altán Redes acordaron con el IFT el acceso gratuito a contenidos oficiales sobre el coronavirus (IFT, 2020b). Del mismo modo, en Brasil se estableció que el uso de la aplicación "Coronavirus SUS" para monitoreo de la pandemia entre la población no consuma datos.

Por su parte, los operadores permiten el acceso sin costo de datos a aplicaciones gubernamentales y a los principales medios de comunicación en Brasil (CAF, 2020). Por ejemplo, empresas como Claro, principal operador de telefonía móvil y TV paga en ese país, adoptó de modo voluntario medidas para proveer Wifi de manera gratuita en lugares públicos y aeropuertos, otorgar a sus clientes de prepago acceso de una hora a mensajes del Ministerio de Salud, liberar señales de TV por tiempo limitado, y acceso a libros, música y juegos gratis para clientes. También otras empresas como Vivo, TIM y Oi adoptaron medidas similares. Del mismo modo, Cablevisión en Argentina liberó el acceso a la aplicación Flow -con contenidos de TV lineal y bajo demanda- de modo gratuito para todos sus clientes.

Por otra parte, en materia de acceso a información crítica y combate a la desinformación, los gobiernos de Argentina y México publicaron anuncios pagos en Google para que, cada vez que alguien busque algo relacionado a la COVID-19, la primera sugerencia del buscador sea la de información oficial sobre la enfermedad provista por la respectiva cartera sanitaria de cada país. Esto implica cuantiosas sumas de ingresos para la plataforma, pero parece ser una acción eficaz para proveer de información confiable a la población.

A nivel global, las bibliotecas, editoriales, publicaciones académicas, museos, plataformas de venta de productos culturales ofrecieron acceso abierto a parte de sus contenidos vinculados específicamente a la pandemia o culturales y de entretenimiento con diversos niveles de apertura y gratuidad, y diferente extensión en el tiempo. Asimismo, incrementaron su actividad algunos sitios que ofrecían acceso abierto a publicaciones liberadas, agotadas o muy difíciles de encontrar así como a otras recientes, lo que suscitó en Argentina acalorados debates sobre los derechos de autor y propiedad intelectual (Fundación Vía Libre, 2020). A nivel global, Creative Commons había lanzado un llamado el 25 de marzo para que en contexto de la pandemia se aceleren las políticas de acceso abierto en el mundo, ya que es necesario contar con el acceso rápido, irrestricto y en los "términos más abiertos posibles" a las investigaciones científicas y materiales educativos sobre COVID-19 (R3D, 2020a). Más de una decena de empresas como como Amazon, Facebook, Microsoft e IBM anunciaron su adhesión a la iniciativa COVID Abierto impulsada por Creative Commons para liberar sus patentes con el propósito de facilitar la investigación sobre COVID-19 (R3D, 2020b). Si bien implican avances en esta coyuntura, también muestran su excepcionalidad y el probable regreso al cierre y pago de contenidos una vez superada la crisis sanitaria. No obstante, pusieron en debate los derechos culturales de acceso a contenidos. 
Las políticas estatales de los tres países considerados en asociación con prestadores privados para garantizar el derecho al acceso a la conectividad y a los contenidos de salud, educación y entretenimiento disponibles on line son progresivas en materia de derechos humanos. Sin embargo, se registran diferencias importantes de profundidad y alcance de las medidas.

\subsection{Privacidad}

Durante el avance del SARS-CoV-2 en América Latina y las medidas para prevenir y mitigar la enfermedad que produce, se discute la utilización de datos personales para vigilancia y control de la población para monitorear la transmisión del virus, y la apropiación y venta de datos personales con fines comerciales.

Vigilancia estatal: Igual que en otros países del mundo, gobiernos de América Latina han comenzado a utilizar información de los teléfonos móviles y de sus aplicaciones con el propósito de controlar la expansión del SARS-CoV-2, aun cuando no siempre resguardan lo suficiente derechos individuales fundamentales, no está claramente justificada su absoluta necesidad e irremplazabilidad por metodologías menos intrusivas, ni queda claro que estas medidas puedan desmantelarse una vez superada la situación de excepcionalidad.

Las aplicaciones de autoevaluación de síntomas de COVID-19 del gobierno argentino y de monitoreo del cumplimiento de la cuarentena obligatoria que éste solicitaba que instalen los residentes que llegaban al país, incluyen la geolocalización con el expreso consentimiento informado de quien la usa. Además, el número de WhatsApp dispuesto por el gobierno argentino para recibir consultas facilitando el autoexamen, permiten a la vez identificar números telefónicos y por esa vía a las personas que buscan esa información (Lara, 2020). En algunos estados mexicanos como Ciudad de México anunciaron la implementación de georreferenciación de telefonía móvil para monitorear movimiento y contacto y controlar el aislamiento social (Lara, 2020); en Baja California se comenzaron a utilizar estas tecnologías de "trazabilidad" para establecer cercos sanitarios y focalizar la atención sanitaria en los sitios con mayor concentración de casos de enfermedad (Rojas, 2020); u otros estados donde las autoridades dirigen solicitudes de información a las empresas de telecomunicaciones, "sin condición alguna de transparencia para medir su cumplimiento de los estándares de derechos humanos y de la legislación nacional" (Lara, 2020). En Brasil, en cambio, el presidente Bolsonaro rescindió un acuerdo entre empresas de telecomunicaciones y el Ministerio de Ciencia, Tecnología, Innovación y Comunicación para facilitar información sobre teléfonos móviles relativas a ubicación geográfica y movilización. La decisión se debió más a su política temeraria frente a la pandemia antes que a la protección de los datos personales. No obstante, las autoridades estaduales tienen potestad para implementarlas (Lara, 2020).

Ante las informaciones de la prensa brasileña sobre proyectos de recopilación y procesamiento digital de datos de movilidad de usuarios de servicios de telecomunicaciones con fines sanitarios y de seguridad, la ANATEL (2020e) advirtió que esto debe estar sujeto a la legislación vigente y, sobre todo, a la Constitución Federal; que "la ponderación de la protección entre la salud y la privacidad está en el más alto grado de nuestra jerarquía normativa"; que incluso en la crisis actual es posible la "armonización entre los dos bienes jurídicos". Sostuvo también que, en la medida en que los derechos individuales pueden ser afectados, se debe observar la "proporcionalidad" del juicio, la relación costo-beneficio, la posibilidad de alternativas menos invasivas y el consenso individual (ANATEL, 2020e). "La cultura de la protección de la privacidad, aunque está creciendo, es todavía incipiente en el Brasil. En un escenario en el que la 
conciencia de los individuos sobre el tema es puntual, corresponde al Poder Público protegerlos en varias dimensiones cuyos reflejos pueden ser mucho más permanentes que la crisis actual" (ANATEL, 2020e).

Ante esto, iniciativas cívicas y académicas ofrecieron su expertise, pero también compañías de tecnologías de vigilancia como NSO Group ven una enorme oportunidad de negocios y buscan convertir en deseables tecnologías que fueron utilizadas recientemente en la región para espiar a periodistas y activistas como se comprobó en México y Guatemala (EFF, 2018).

Los Relatores de Libertad de Expresión de Naciones Unidas, la Organización de Estados Americanos y la Unión Europea solicitaron a los gobiernos limitar el uso de tecnologías de vigilancia para rastrear la propagación del virus. La CIDH (2020) también recomendó garantizar el derecho a la privacidad y el tratamiento de datos personales de pacientes y personas que se realizan exámenes durante la pandemia.

También la coalición de organizaciones de la sociedad latinoamericana Al Sur y más de 100 organizaciones a nivel global demandaron a los gobiernos que el uso de tecnologías digitales con uso de información sensible y de localización en este contexto respete los derechos humanos y advirtieron sobre su posible irreversibilidad a futuro. La organización mexicana Derechos Digitales advierte que el uso de estas tecnologías presenta "incontables puntos de duda: cómo se anonimizará y agregará la información para no identificar individuos, quién tiene acceso a la información, cómo será utilizada (y en contraste con qué otros datos), por cuánto tiempo y bajo qué condiciones se almacenará, etcétera" mientras que "su utilidad en relación con sus niveles de penetración, en tanto, son todavía un misterio" (Lara, 2020).

Venta de datos personales: Por otra parte, se puso en debate también la apropiación y venta de datos personales con fines comerciales al conocerse la venta de datos que, a nivel global, hizo la plataforma para videoconferencias Zoom a la red social Facebook. Zoom se vio obligada a dar explicaciones. Ante esto, organizaciones sociales que desarrollan software libre en Argentina se asociaron con el Estado nacional e instalaron Jitsi en Arsat para ofrecer una opción libre, gratuita, sin filtración de información y respaldada con suficiente capacidad de infraestructura para soportar muchas videoconferencias masivas simultáneas que permitan ser una opción para las instituciones de salud. Además, algunas universidades nacionales como la de Entre Ríos también instalaron Jitsi para dar clases y hacer reuniones online.

La inusitada expansión de la vigilancia y control estatal por medio de tecnologías digitales para monitorear la posible transmisión del virus implica una importante regresión en materia de derechos humanos que será difícil de revertir en el escenario post-pandemia. Lo mismo sucede con la apropiación de datos personales y su venta comercial por parte de las plataformas de e-learning y teletrabajo.

\section{Coyuntura socio-política}

El estado de las relaciones de fuerza entre gobiernos, empresas de telecomunicaciones y organizaciones de activismo digital en cada país, junto con la infraestructura de conectividad y las políticas públicas de telecomunicaciones permiten entender en qué condiciones llega la pandemia y se toman las medidas de aislamiento en cada país, y qué posibilidades tiene cada uno de adoptar estrategias más o menos progresivas en materia de derechos digitales. 


\subsection{Infraestructura y políticas públicas}

Las medidas de aislamiento dispuestas o recomendadas en Argentina, México y Brasil para mitigar el impacto de la COVID-19 convirtió a la infraestructura para asegurar la conectividad a Internet en crucial para asegurar la continuidad de los procesos educativos en todos los niveles, el teletrabajo, el comercio on line, las comunicaciones y el esparcimiento. Asimismo, frente a los problemas de privacidad, acceso y libertad de expresión que se presentaron en esta coyuntura, es fundamental revisar las políticas de protección de datos personales, conectividad y moderación de contenidos, neutralidad de la red y concentración.

Infraestructura de conectividad: En este contexto, se pusieron de manifiesto nuevamente las profundas desigualdades que tiene la región en la infraestructura de acceso. Además de que casi la mitad de la población latinoamericana no tiene acceso a Internet o tiene mala calidad de conexión, se registra mucha desigualdad entre países, regiones de cada país, zonas rurales y urbanas, varones y mujeres, jóvenes y viejos, etc. (CEPAL, 2017). En Argentina, la penetración de Internet en los hogares alcanza el 65,8\%, pero hay varias provincias con niveles inferiores al 40\% (CABASE, 2019). En México, la penetración es de 55 accesos residenciales cada 100 hogares, mientras en Ciudad de México se registran $84 \%$ de accesos, en ciudades como Oaxaca o Chiapas no llegan a 20\% (IFT, s/f a y b). En Brasil, de acuerdo con ANATEL (2020d), hay 33 millones de accesos residenciales, lo cual representa una penetración del 47,4\%. En Brasilia y Santa Catarina, los accesos superan el 70\%, pero en los estados del norte apenas llegan al 30\%.

En Argentina, más de la mitad de las conexiones a nivel nacional se produce con tecnologías viejas -cablemodem- mientras que con fibra óptica lo hace sólo entre el 3,5\% (CABASE, 2019) y el 10\% (Carrier, 2019 e Iglesias, 2019), según las metodologías de registro consideradas. En México, la principal tecnología de acceso es el cable coaxial (39\%), seguida del DSL (35\%) y el $25 \%$ de los accesos son por fibra óptica (IFT, s/fb). En Brasil, un dato distintivo respecto de Argentina y México es que la fibra óptica ya alcanza casi la misma participación como principal tecnología de acceso que el cablemodem (31\% y 31,4\% respectivamente), en tanto el cable coaxial representa el 29\% de los accesos a nivel nacional (ANATEL, 2020d). Los tres países forman parte del Top 10 del Índice de Desarrollo de la Banda Ancha (IDBA) en América Latina y el Caribe del Banco Interamericano de Desarrollo (García Zaballos \& Iglesias, 2019). A su vez, el predominio de tecnologías de cablemodem y par de cobre para la conectividad demuestra que aún dependen de tecnologías más antiguas, lo que representa un obstáculo para la oferta de un servicio con mayores velocidades. Al mismo tiempo los crecientes niveles de fibra óptica, dan cuenta de la realización de inversiones por empresas locales grandes operadores de telecomunicaciones (Telesemana, 2020), e inversiones estatales.

Políticas y regulaciones de telecomunicaciones e Internet: Las políticas públicas vinculadas con los desafíos de privacidad, acceso y libertad de expresión planteados durante la expansión de la COVID-19 y las medidas de aislamiento preventivo dispuestas son las de protección de datos personales, conectividad, neutralidad de la red, responsabilidad de los intermediarios, y concentración, respectivamente.

En primer lugar, los tres países tienen leyes de protección de datos personales. México cuenta con la Ley Federal Mexicana de Protección de Datos Personales en Posesión de los Particulares (2010) y Ley General de Protección de Datos Personales en Posesión de Sujetos Obligados (2016) que es específica para el sector público. Las normas establecen que los datos personales sólo pueden ser tratados con consentimiento del titular y obtenidos de manera libre, específica e informada y, en el caso de datos personales sensibles, financieros o patrimoniales, el consen- 
timiento debe ser expreso. La autoridad de aplicación es un órgano autónomo e independiente con amplias facultades de investigación, sanción y consulta (ADC, 2016). En Brasil, la Ley General de Protección de Datos Personales aprobada en 2018 crea una autoridad nacional, incorpora el alcance extraterritorial, obliga a empresas y organismos gubernamentales que traten datos personales a nombrar un oficial de protección de datos; y prevé multas por incumplimiento (Bojalil \& Vela -Treviño, 2019). Sin embargo, la normativa aún no ha entrado en vigor. Si bien estaba previsto que eso suceda en agosto de 2020, cuando comenzó la expansión del SARS-CoV-2 en la región se presentaron proyectos en el Congreso solicitando su postergación con el argumento de la falta de capacidad financiera durante la crisis de micro y pequeñas empresas para adecuarse a sus disposiciones (Gondim, 2020). La Coalición por los Derechos en la Red advirtió que la entrada en vigor de la ley no representa la aplicación inmediata de sanciones y prevé plazos de adecuación (CDR, 2020). Argentina ha sido pionera al sancionar en 2000 una de las las primeras leyes de protección de datos personales en la región, pero esta norma quedó anacrónica frente a la digitalización (Becerra, 2019). En 2016 la Ley de Derecho de Acceso a la Información Pública creó la Agencia de Acceso a la Información Pública como autoridad de aplicación de ambas leyes que, desde 2017, integra con autonomía funcional la Jefatura de Gabinete de Ministros.

Sobre la responsabilidad de los intermediarios de Internet, desde 2013 hay iniciativas en la región para regular contenidos en Internet y a los intermediarios de Internet (CELE, 2018). El Marco Civil da Internet en Brasil establece que los intermediarios de internet no pueden ser responsabilizados por contenidos generados por terceros, a menos que reciban una orden judicial y no lo remuevan, en cuyo caso se estipulan penas de cárcel (Aguerre \& Levy, 2019). Ni en Argentina ni en México existe un marco legal sobre este tema. En Argentina hay fallos judiciales y en 2018 se aceleró el debate parlamentario pero no prosperó, obstaculizado por las presiones de la industria de copyright, empresas periodísticas y plataformas globales (Observacom, 2018; Aguerre \& Levy, 2019). En México, el Tratado entre México, Estados Unidos y Canadá de 2018 limita la responsabilidad civil de las plataformas sobre contenidos de terceros excepto cuando involucra a derechos de autor, en cuyo caso se establece el mecanismo de notificación y retirada de contenidos, dejando en manos de los intermediarios la decisión de removerlos, sin debido proceso (Bizberge, 2018).

En relación a las políticas de conectividad, a inicios del siglo XXI, después de las políticas de desregulación y privatización de los 90, en los tres países se había registrado un cambio en el papel del Estado que entonces invirtió en el despliegue de infraestructura de red y el desarrollo de servicios de banda ancha (Galperín, Mariscal y Viecens, 2013). Así, en Argentina, desde 2010 se desarrolla el Plan Argentina Conectada (ver Baladrón, 2018) y en Brasil, el Plan Nacional de Banda Ancha (ver Intervozes, 2018). En ambos casos, los operadores estatales, Arsat y Telebrás, tienen un rol central en el desarrollo de las redes troncales de fibra. En México se despliega la Agenda digital.mx, pero con un modelo de asociación público-privada (ver Galperín, Mariscal y Viecens, 2013).

En articulación con la ampliación de la conectividad a Internet de banda ancha (sobre todo en Argentina y Brasil), en 2014 se sancionaron normativas sobre telecomunicaciones e Internet en los tres países: en México, la Ley Federal de Telecomunicaciones y Radiodifusión (LFTR); en Argentina, la Ley Argentina Digital; y en Brasil, el Marco Civil de Internet. Los tres países reconocieron en el mismo momento la noción de neutralidad de red que implica que acceso abierto y trato equitativo del tráfico de información en internet (Wu, 2003). Sin embargo, en los tres casos su implementación ha encontrado limitaciones. En México y Argentina, por falta de reglamentación, lo que limita el campo de acción de los reguladores para garantizar y fiscalizar su cumplimiento (Bizberge, 2019). 
En Brasil, donde sí hay reglamentación, las dificultades se deben al lobby empresarial de las telefónicas que consideran que la prohibición de prácticas de zero rating afecta su modelo de negocio, sumado a una mirada permisiva del regulador y del organismo de defensa de la competencia (Bizberge, 2019).

Por otra parte, en los tres países se introdujeron definiciones sobre dominio de mercado y mercados relevantes de telecomunicaciones (en Argentina y México a través de las leyes mencionadas y en Brasil por medio del Plan General de Metas de Competencia que se desprende del proceso de privatización las telecomunicaciones), junto con criterios de regulación asimétrica que incluye la posibilidad de controlar la concentración y promover la competencia en el mercado (Bizberge, 2019). Sin embargo, en los tres países los niveles de concentración de la propiedad se mantuvieron e incluso se agudizaron debido a la combinación de estrategias de mercado y políticas públicas en nombre de la competencia de redes, promoción del acceso y la convergencia digital, especialmente a partir de 2015 y 2016 con la llegada de gobiernos de derecha en Argentina y Brasil (Bizberge, 2019). En particular, en Argentina, el gobierno de Macri autorizó la fusión en 2017 entre el principal operador de banda ancha y TV por cable en el país, Cablevisión (Grupo Clarín) y Telecom, actor central para comunicaciones fijas, móviles y banda ancha, lo que constituyó un hito en la región. En Brasil, en tanto, los esfuerzos de los gobiernos de primeros 15 años del siglo XXI, se habían centrado en la promoción del acceso, evitando una discusión sobre los niveles de concentración de la propiedad y participación de mercado de las principales empresas del sector que consolidaron sus posiciones (Becerra y Mastrini, 2017). En México, la reforma constitucional de 2013 así como la LFTR de 2014 plantearon mecanismos para limitar la concentración con medidas de regulación asimétrica, pero éstas resultaron insuficientes.

En síntesis, la creciente dependencia social de la conectividad a Internet debido a las medidas de aislamiento preventivo durante el avance de la COVID-19, encontraron a Argentina, Brasil y México con alrededor de la mitad de su población sin conectividad de banda ancha en sus hogares, altísimos niveles de desigualdad geográfica, y tecnologías viejas a pesar de los avances realizados en ese sentido, lo que hace comprensible la preocupación de la población por el acceso en esta coyuntura, y las medidas tomadas por los gobiernos y las iniciativas de la sociedad civil para garantizarlo. Aunque las previsiones de leyes de telecomunicaciones, Internet o convergentes sobre medidas anti-concentración de los tres países avanzan en sentido más o menos progresista, los mayores obstáculos se registran en la etapa de implementación de las normas por limitaciones a las competencias del regulador o aplicación sesgada por fines políticos y económicos. Esto explica -como se indica en la próxima sección- los elevados niveles de concentración de la propiedad en las empresas proveedoras de servicios de acceso a internet. El criterio de rentabilidad que aplican contribuye a las desigualdades en el acceso, velocidad y calidad de conexión, que las políticas públicas intentan contrarrestar.

En tanto, si bien los tres países tienen leyes de protección de datos personales, se comprenden los problemas de privacidad ocasionados tanto por gobiernos como por corporaciones durante el control de la pandemia, porque en un caso esta ley es obsoleta y en otro aún no está en vigencia. Por otra parte, aunque en los tres países está consagrado el principio de neutralidad de la red (a pesar de las limitaciones en su implementación), en un contexto excepcional de emergencia se admite el trato discriminatorio para ofrecer sin consumo de datos contenidos considerados críticos o socialmente relevantes como los de salud y educación. Finalmente, los vacíos en la regulación de intermediarios en Internet permiten explicar los problemas de censura privada automática y de promoción gubernamental de la autocensura que se registraron en esta coyuntura. 


\subsection{Actores: empresas, gobiernos y sociedad civil}

Las empresas de telecomunicaciones, los gobiernos y las organizaciones de activistas digitales son los principales actores que no sólo están condicionados por la infraestructura y las políticas públicas, sino que son quienes las producen y modifican.

Operadores privados: América Latina se caracteriza por altos niveles de concentración de la propiedad en los servicios de comunicación. En los tres países estudiados dos grandes grupos dominan el mercado infocomunicacional: Clarín y Telefónica en Argentina; Televisa y América Móvil en México; y Globo y América Móvil en Brasil. En materia de conectividad, en México y Argentina, el principal proveedor del servicios de internet por banda ancha fija controla alrededor de la mitad del mercado. En Argentina, Telefónica focaliza su negocio en servicios de telecomunicaciones y acceso a Internet, luego de que en 2016 vendiera a Viacom el canal de televisión abierta Telefé, único que la empresa mantenía en la región. Por su parte, Clarín centra sus actividades en medios, conectividad a internet y telecomunicaciones fijas y móviles, tras su fusión con Telecom. Como multimedio dominante, Clarín tiene competencia en los mercados en los que opera pero es el líder en casi todos los segmentos (Becerra \& Mastrini, 2017). Es el principal cableoperador a través de Cablevisión, con el $41 \%$ del mercado y controla casi la mitad del mercado de banda ancha (46\% luego de la fusión con Telecom), seguido de lejos por Telefónica (17\%), Telecentro (12\%), Supercanal (6\%), AT\&T (1\%), otros (18\%) (Becerra \& Mastrini, 2017 y CABASE, 2019). En Brasil, la concentración está repartida, por un lado, en el sector de medios con el predominio de Globo y, por el otro, en el sector de telecomunicaciones con el amplio dominio de Claro y Telefónica. Entre ambas controlan más del 50\% del mercado de telefonía, Internet y empaquetamiento/distribución de TV de pago. En telecomunicaciones también se destacan Oi (Telemar y Portugal Telecom) y TIM, subsidiaria de Telecom Italia, pero solo tiene en telefonía móvil. Entre los cuatro se reparten el 85\% de los ingresos de los mercados del sector de telecomunicaciones (Becerra y Mastrini, 2017). En el país, el 65\% del mercado de banda ancha está concentrado en tres operadores: Claro $(29,1 \%)$, seguido de Vivo -Telefónica- (21,3\%) y Oi (15,9\%), de acuerdo con cifras del 2019 de ANATEL. En México, América Móvil cubre el 50,6\% de la conectividad a banda ancha fija, Televisa el 24,3\%, Megacable 15,7\%, TotalPlay 7,7\% y,otros 1,6\% (IFT, 2019). En las telecomunicaciones móviles, si bien hubo cierta apertura con el ingreso de AT\&T para competir con América Móvil y Movistar, su llegada vino de la mano de la reducción de actores que participaban en ese mercado (adquirió a Nextel y Iusacell) (Bizberge, 2019). El mercado de telefonía móvil tiene como actor dominante a América Móvil (69,8\%); seguido de AT\&T (17\%), Telefónica (11,3\%), otros (2\%), de acuerdo con el IFT. Por su parte, Televisa -que también opera en telecomunicaciones- consolidó aún más su poder en el mercado de TV paga con el 63,6\% del mercado mientras que su competidor directo, Megacable, no llega al 16\% (Bizberge, 2019).

Gobiernos: Los tres países tienen gobiernos con diferentes orientaciones políticas. En Brasil, después del proceso de impeachment a la ex presidenta Dilma Rousseff del Partido dos Trabalhadores (PT) en 2016 y la asunción de Michel Temer, el proceso electoral que consagró a Jair Bolsonaro como presidente desde 2019 marcó el giro a la derecha de ese gobierno. Bolsonaro se erigió como alternativa política en nombre de la lucha contra la corrupción, con su habilidad para presentarse como político anti-establishment en relación a la clase política tradicional de Brasilia a pesar de haber cumplido su séptimo mandato en la Cámara de Diputados, y sus fuertes vínculos con militares (es militar retirado) y grupos fundamentalistas religiosos (Goldstein, 2019). En México, el presidente Antonio Manuel López Obrador (AMLO) asumió en 2018 encabezando un frente de partidos heterogéneos, con una propuesta progresista. Es el presidente 
más votado en la historia reciente del país, en comicios muy concurridos, y le ganó al Partido Revolucionario Institucional (PRI) que había controlado el país durante 70 años consecutivos, excepto por dos períodos de gobierno en 2000-2012 cuando había ganado el conservador Partido de Acción Nacional (PAN), con el que de todos modos el PRI mantuvo una alianza de facto y continuidad política (BBC Mundo, 2018). Se presentó también como un candidato outsider de la política tradicional, aunque hasta 2011 había sido integrante del Partido de la Revolución Democrática. En tanto, en Argentina, en 2019 asumió Alberto Fernández con la ex presidenta Cristina Fernández como vicepresidenta, por el Frente de Todos liderado por el tradicional Partido Justicialista, con la propuesta de restablecer una agenda progresista luego del primer gobierno de derecha electo por el voto popular que había tenido Argentina, al tiempo que reivindicaba su trayectoria política y la de su alianza electoral. Si bien los presidentes tienen distinta capacidad de negociación con los parlamentos de sus países, durante la emergencia las decisiones se centran en el Ejecutivo.

Los modos en que cada gobierno encaró la pandemia de la COVID-19 son muy diversos. Bolsonaro negó la gravedad de la amenaza e instó a la población brasileña a desobedecer las medidas de aislamiento dispuestas por los gobernadores estaduales. AMLO primero minimizó los riesgos y luego recomendó el aislamiento. Fernández, en cambio, rápidamente decretó el aislamiento social preventivo y obligatorio en todo el territorio argentino, apenas 3 meses después de haber asumido como presidente con el $48 \%$ de los votos.

Esto incidió fuertemente en sus niveles de apoyo popular. El presidente argentino alcanzaba a fines de abril un promedio de $76 \%$ de imagen positiva en todo el país y menos del 5\% de imagen negativa (Berra, 2020). Estos niveles inéditos de adhesión que subieron alrededor de 20 puntos durante el manejo de la pandemia muestran la aprobación de las medidas sanitarias dispuestas. En México y Brasil, en cambio, la imagen de los presidentes está en baja y, entre otros factores, la desaprobación popular por el manejo de la crisis sanitaria juega un rol importante. AMLO tenía a mediados de abril un nivel de aprobación del 46,5\% y había perdido casi 12 puntos desde principios de año, según Consulta Mitofsky (citada en Infobae, 2020). En Brasil, Bolsonaro enfrenta la peor crisis desde su asunción: su imagen positiva cayó al 33\% y la Asociación de Juristas Brasileños para la Democracia (ABJD) lo denunció por su "irresponsable" gestión de la emergencia sanitaria (La Voz del Interior, 2020b).

Sociedad civil: Los tres países cuentan también con numerosas organizaciones de la sociedad civil conformadas por profesionales y expertos técnicos que promueven políticas públicas para regular las prácticas corporativas de apropiación y venta de datos y de censura privada, y para frenar el poder de los estados en acceso, producción, protección y administración de datos, y el acceso a la tecnología a través de software libre y hardware abierto.

Muchas de las organizaciones latinoamericanas de activistas digitales son capítulos nacionales de organizaciones internacionales abocadas a libertad de expresión y acceso a la información que antes trabajaban sobre tecnologías analógicas, como Artículo 19-México o Artículo 19-Brasil. Otras son organizaciones no gubernamentales internacionales, regionales o nacionales de derechos humanos surgidas en décadas anteriores que empezaron a incluir los derechos digitales en sus agendas, como la Asociación por los Derechos Civiles o el Centro de Estudios Legales en Argentina, o Amnistía Internacional en muchos países de la región y Transparency Internacional. Algunas otras son organizaciones de derechos digitales locales, surgieron en la década de 2000 en la región, como la Fundación Argentina Vía Libre, una de las primeras organizaciones latinoamericanas de este tipo que se creó en 2000. (Segura, 2019) 


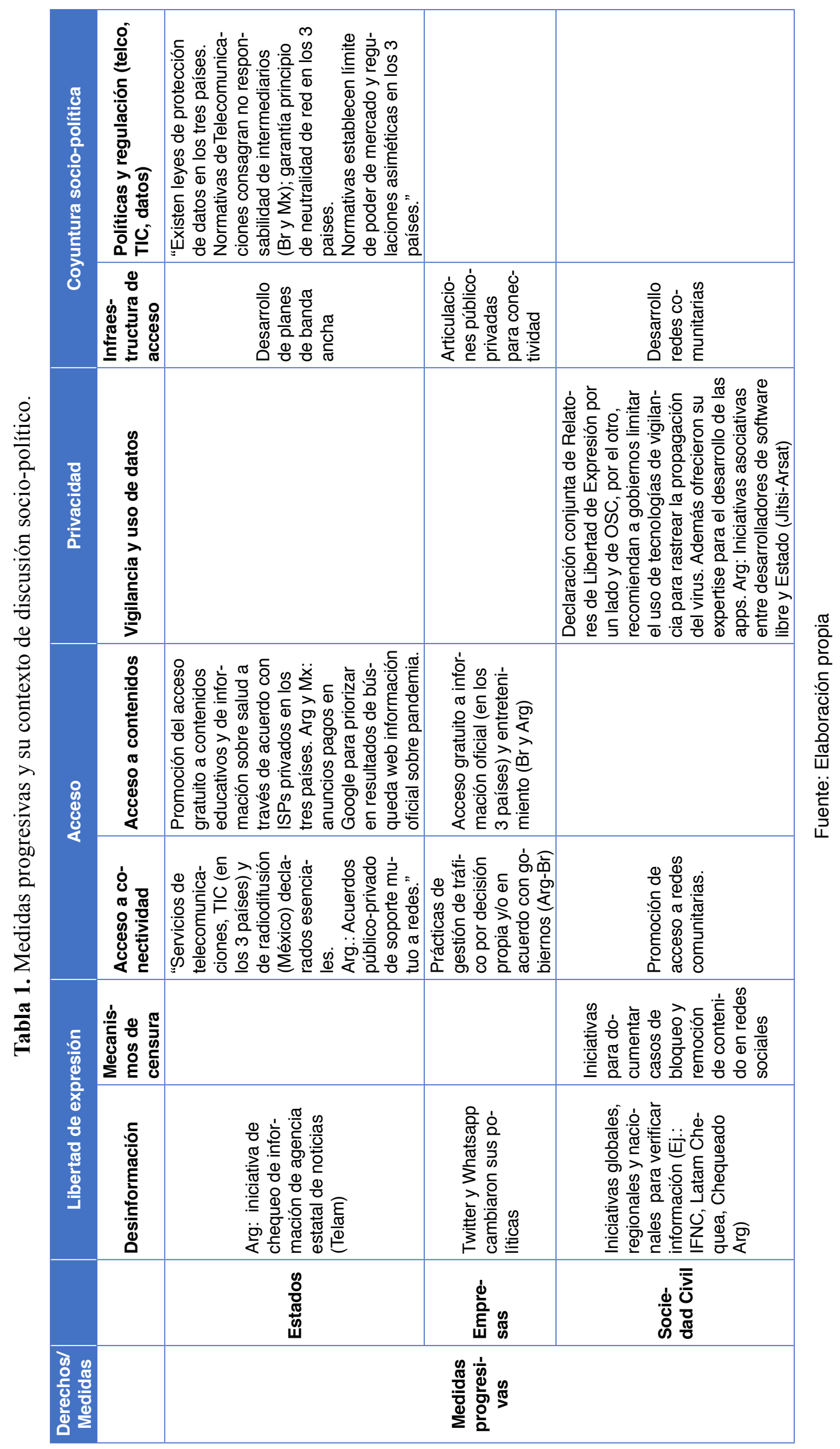







En los últimos años estas organizaciones se han articulado de diversas maneras para unir recursos, capacidades, conocimientos, herramientas, relaciones y, por lo tanto, poder de incidencia. Conforman redes con diversos fines a corto, mediano o largo plazo. También mantienen diversas relaciones con el Estado y el mercado. Así como hay organizaciones autonomistas que se mantienen más alejadas de estos otros dos sectores poderosos, otras mantienen vínculos complejos. (Segura, 2019)

El activismo por los derechos digitales se inició simultáneamente con la movilización de las organizaciones que impulsaron reformas en las políticas de comunicación (Segura y Waisbord, 2016; Segura, 2018) y cultura (Prato y Segura, 2018), que lograron inéditos niveles de incidencia en la región. Al compartir, en términos generales, el marco normativo de los derechos humanos, su incidencia se potencia mutuamente $y$, en no pocas ocasiones, encuentran sinergias para estrategias conjuntas como, por ejemplo, la organización mexicana Rizhomática que desarrolla telefonía celular comunitaria y redes comunitarias de internet. Además, se inició en el momento de auge de gobiernos progresistas durante los primeros quince años del siglo XXI en muchos de los países de la región que, aunque no fueron los únicos, fueron ideológicamente más proclives que otros a avanzar en políticas de acceso abierto, software libre y neutralidad de la red. (Segura, 2019)

En síntesis, la adopción de medidas de respuesta a la pandemia se enmarca en una trama de relaciones de poder entre actores privados, Estado y sociedad civil con distinto grado de fortaleza. Se parte de un escenario con agudos niveles de concentración de la propiedad, especialmente en conectividad, lo que deja a los Estados escaso margen de maniobra para establecer regulaciones que afecten intereses empresariales incluso en la crisis. De hecho, las medidas adoptadas para garantizar conectividad, por ejemplo, han sido suaves y consensuadas con esos actores. Además, dos de los tres presidentes de los países estudiados sufrieron bajas en sus niveles de apoyo popular, entre otros factores, debido a los abordajes que hicieron de la pandemia. En cambio, la sociedad civil de los tres países, aunque es heterogénea, está consolidada, ha ganado poder de incidencia en los últimos años y tiene experiencia acumulada en relación a los debates sobre reformas del audiovisual, por lo que consigue hacer oír su voz pública en los debates sobre derechos digitales durante la expansión del COVID-19 y las medidas de aislamiento adoptadas.

A continuación, las Tablas 1 y 2 sintetizan los tipos de medidas (progresivas o regresivas) adoptadas durante la pandemia en el período analizado en este artículo por parte de Estados, Empresas y Sociedad Civil y los principales aspectos del contexto socio-político en el que las mismas fueron adoptadas.

\section{Conclusiones}

Los ejes de debate sobre internet durante la pandemia y el aislamiento en América Latina giran en torno a tres tipos de derechos digitales: el de acceso, el de privacidad y el de libertad de expresión, y cada uno de estos derechos se ve afectado por varias clases de problemas ocasionados por los gobiernos y/o por las empresas de internet y telecomunicaciones: de conectividad, geolocalización de pacientes, censura, desinformación.

Las políticas estatales incluyeron algunas medidas regresivas como la propagación oficial de desinformación, la promoción de la autocensura, y la vigilancia, y otras progresivas a veces en asociación con la sociedad civil como las tendientes a garantizar el acceso a la conectividad y a contenidos on line de manera gratuita. Las diferencias entre los países se vinculan con la orientación política del gobernante, con el enfoque del conjunto de políticas públicas con las que se enfrentó el avance del COVID-19, y con las diferentes relaciones de fuerza existentes 
entre los actores involucrados: proveedores de conectividad y redes sociales con agudos niveles de concentración; gobiernos con escaso margen de maniobra en la búsqueda del equilibrio entre la ecuación política y económica; y una sociedad civil que, aunque heterogénea, consigue hacer oír su voz pública en los debates.

En tanto, las empresas de Internet desarrollaron a nivel global estrategias regresivas de las que, en ciertos casos como las posibilidades de expansión de noticias falsas, la censura automática, o de venta de datos personales de las plataformas de videoconferencia, tuvieron que dar marcha atrás u ofrecer explicaciones o alternativas de solución. En relación a las empresas de conectividad (ISPs), en alianza con los gobiernos adoptaron medidas que contribuyeron a la ampliación de derechos como la liberación de acceso a contenidos y establecimiento de planes de servicio mínimos para mantener las condiciones de acceso a la información y la comunicación, aunque se trata de medidas temporales.

La sociedad civil de cada país procuró incidir en los gobiernos para impulsar soluciones progresivas y, en algunos casos, pudo ofrecer alternativas que contribuyeron a solucionar los problemas, como la verificación de datos, las redes comunitarias de internet, las plataformas de videoconferencias de software libre, y los acuerdos de acceso abierto.

En situación de riesgo se toman medidas excepcionales que pueden sentar precedentes adversos como las prácticas de vigilancia y censura estatal y privada. Sin embargo, constituyen también una oportunidad para construir alternativas progresistas, viables y sostenibles en el tiempo como el zero rating para garantizar acceso a plataformas de educación virtual, las redes comunitarias de internet o el software libre. La crisis es también terreno fértil para plantear debates sobre los derechos digitales con un alcance social mucho más amplio. Del activismo social y las decisiones estatales depende que esta situación adversa constituya una ventana de oportunidad para garantizar y ejercer más y mejores derechos.

\section{Bibliografía}

ADC (2016). El sistema de protección de datos en América Latina. Oportunidades y desafíos para los derechos humanos. Asociación por los Derechos Civiles (ADC). https://bit.ly/33D1SHh

Aguerre, C. \&Levy Daniel, M. (2019). Intermediarios de Internet: consideraciones para reflexionar en el contexto de Argentina. Universidad de San Andrés. Departamento de Derecho. Centro de Estudios de Tecnología y Sociedad. https://bit.ly/2PvqdXt

Amnesty International-Argentina (2018). El debate público limitado: trolling y agresiones a la libertad de expresión de periodistas y defensores de DDHH en Twitter Argentina. Amnesty International-Argentina. https://bit.ly/3kkM4PG

ANATEL (20 de marzo de 2020). Anatel e setor de telecom firmam compromisso público para manter Brasil conectado. https://bit.ly/31sukcj

ANATEL (16 de abril de 2020b). Decisão do TRF3 suspende liminar que proibia cortes e Anatel emite comunicado às prestadoras de telefonia fixa e móvel. https://bit.ly/2EPKTqX

ANATEL (7 de abril de 2020c). Radiodifusores e empresas de streaming reafirmam seu compromisso com os serviços". https://bit.ly/2XCDu4R

ANATEL (2020d). Relatorio de acompanhamiento banda larga fixa 4 trimestre 2019. ANATEL. https://bit.ly/3gGZzac 
ANATEL (15 de abril de 2020e). Posicionamento da Anatel a respeito da utilização de rastreamento de usuários de telecomunicações no âmbito de medidas no combate à pandemia de Covid-19. https://bit.ly/3ifXsdx

APC (2020). Más cerca que nunca: Qué hacer para que nuestros movimientos se mantengan conectados e inclusivos - Respuesta de la Asociación para el Progreso de las Comunicaciones frente a la pandemia de COVID-19. APC. https://bit.ly/33MvnXB

Baladrón, M. (2018). El Plan Nacional de Telecomunicaciones Argentina Conectada (20102015) en el marco de las políticas públicas de universalización del acceso a internet. Tesis de la Maestría en Industrias Culturales: Políticas y Gestión de la Universidad Nacional de Quilmes, Bernal. http://ridaa.unq.edu.ar/handle/20.500.11807/788

Becerra, M. (12 de agosto de 2019). La economía de datos y los derechos ciudadanos. Colsecor Revista. https://bit.ly/2XxDItV

BBC News Mundo (7 de abril de 2020b). 'Gripezinha ou resfriadinho' e outras 7 frases controversas de líderes mundiais sobre o coronavírus. https://www.bbc.com/portuguese/ internacional-52205918

BBC News Mundo (2 de julio de 2018). López Obrador gana en México: ¿por qué es histórico el triunfo de AMLO en la elección presidencial mexicana? https://www.bbc.com/mundo/noticiasamerica-latina-44678613

Becerra, M. \& Mastrini, G. (2017). La concentración infocomunicacional en América Latina (2000-2015). Editorial UNQ -Observacom.

Berra, N. (8 de mayo de 2020). Por qué fracasó el 7 M. CBA24N. https://bit.ly/2PwEIu0

Bertolini, P (23 de marzo de 2020). El tráfico de datos registró incrementos de más del $25 \%$ en promedio en la última semana en América Latina. DPL News. https://bit.ly/3koCkE6

Bizberge, A. (16 de abril de 2020). Medios y COVID-19 en América Latina. OBSERVACOM. https://www.observacom.org/medios-y-covid-19-en-america-latina/

Bizberge, A. (27 de marzo de 2020b). Acceso a Internet y gestión de redes de telecomunicaciones ante el COVID-19 en América Latina. OBSERVACOM. https://bit.ly/2EPLk15

Bizberge, A (2019). Alcances y desafios de la convergencia digital y su impacto para la elaboración de políticas de comunicación. Un estudio de la convergencia regulatoria en Argentina, Brasil y México (2000- 2017). Tesis para optar al título de Doctora en Ciencias Sociales. Facultad de Ciencias Sociales. Universidad de Buenos Aires (UBA). Ciudad de Buenos Aires.

Bizberge, A. (26 de noviembre de 2018). USMCA: México cedió su soberanía cultural en internet a Estados Unidos. LetraP. https://bit.ly/30zrYJt

BBC News Mundo (27 de abril de 2020). Coronavirus: el mapa interactivo que muestra las medidas o distintos tipos de cuarentena que adoptaron los países de América Latina. https://www. bbc.com/mundo/noticias-america-latina-52248497

Bojalil, P. \& Vela -Treviño, C. ( 12 de febrero de 2019). Despuntan las reformas en materia de protección de datos en América Latina. IADB Blog. https://bit.ly/3a50uhT

CABASE (2019). CABASE Internet Index Estado de Internet en Argentina y la Región Segundo Semestre 2019. https://bit.ly/3a8WXz9 
CDR (31 de marzo de 2020). O Estado Brasileiro precisa respeitar o compromisso assumido com a proteção de dados pessoais. https://bit.ly/31vKvpe

CAF (2020). Las oportunidades de la digitalización en América Latina frente al Covid-19. https:// bit.ly/2Py78nE

CAF (S/F). Hacia la transformación digital de América Latina y el Caribe, Observatorio del ecosistema digital. https://www.caf.com/app_tic/\#es/home

Carrier, E. (1 de noviembre de 2019). Hogares fibrados. Comentarios info. https://comentarios. info/index.php/2019/11/01/hogares-fibrados/

Castells, M. (2009). La comunicación en la era digital. Comunicación y Poder. Alianza Editorial.

CELAG (11 de abril 2020). Geografía política del coronavirus en América Latina. https://www. celag.org/geografia-politica-de-coronavirus-en-america-latinal

CELE (2018). La regulación de internet y su impacto en la libertad de expresión en América Latina. CELE. https://bit.ly/30BfXTN

CELS (22 de abril de 2020). Sobre el 'Proyecto de protocolo de ciberpatrullaje. https://bit.ly/3gPAoSy

CEPAL (2017). Estado de la banda ancha en América Latina y el Caribe. UN-CEPAL \& German Cooperation Deustche Zusammenarbeit.

CEPAL (2019). Perspectivas Económicas de América Latina 2019. UN-CEPAL. https:// repositorio.cepal.org/handle/11362/44525

CIDH (2020). Pandemia y derechos humanos en las Américas. OEA. http://www.oas.org/es/cidh/ decisiones/pdf/Resolucion-1-20-es.pdf

CIDH (18 de abril de 2020b). CIDH y su RELE expresan preocupación por las restricciones a la libertad de expresión y el acceso a la información en la respuesta de Estados a la pandemia del COVID-19. https://bit.ly/2DupoM9

CIDH (2019). Guía para garantizar la libertad de expresión frente a la desinformación deliberada en contextos electorales. OEA. https://bit.ly/3kmb5d0

CIDH (2017). Estándares para una Internet Libre, Abierta e Incluyente. / Relatoría Especial para la Libertad de Expresión de la Comisión Interamericana de Derechos Humanos. OEA. https://bit. $1 \mathrm{y} / 3 \mathrm{gC} 86 \mathrm{ed}$

CIDH (2013). Informe Anual 2013. Informe de la Relatoría Especial para la Libertad de Expresión. Capitulo IV (Libertad de Expresión e Internet). OEA. http://www.oas.org/es/cidh/docs/ anual/2013/informes/LE2013-esp.pdf

EFF (30 de diciembre de 2018). Where Governments Hack Their Own People and People Fight Back: 2018 in Review. https://bit.ly/3fz0R5H

El Diario (22 de abril de 2020). Twitter adapta sus normas para atajar la desinformación y el contenido engañoso por el coronavirus. https://bit.ly/3aguaJj

El Universal (22 de marzo de 2020). Pese a coronavirus pide AMLO 'no dejar de salir' ni tomar medidas 'exageradas'. https://bit.ly/2Pzad6Q

Fundación Vía Libre (1era quincena de mayo 2020). El derecho de autor ante la emergencia y el aislamiento. https://bit.ly/3fCXHhl 
Galperín, H., Mariscal, J. y Viecens, F. (2013). Los planes nacionales de universalización. En Jordán, V., Galperín, H y Peres, W. (coords), Banda ancha en América Latina: más allá de la conectividad. CEPAL.

García Zaballos, A. \& Iglesias, E. (2019). Informe Anual del Índice de Desarrollo de la Banda Ancha en América Latina y El Caribe. BID.

Gebreyesus, T. (18 de febrero de 2020). Desinformación frente a medicina: hagamos frente a la 'infodemia”. El País. https://bit.ly/30zu4Ji

Goldstein, A. (2019). Introducción ¿De dónde llegó Jair Bolsonaro?. En. Bolsonaro. La democracia de Brasil en peligro. Marea.

Gondim, A. (15 de abril de 2020). Congreso já registrou 4 PLs para adiar a lei de proteção de dados. Telesintese. https://bit.ly/3gDn83w

GSMA (2 de abril de 2020). Manteniendo todo y a todos conectados: cómo el acceso temporal al espectro puede reducir la congestión durante la crisis del COVID-19"'. https://bit.ly/2C60Yrz

ICSSI (16 de abril de 2020). La cibervigilancia masiva está prohibida. Fundación Vía Libre. https://bit.ly/3fE7hAv

Infobae (13 de abil de 2020). Aprobación de AMLO en picada: lleva 15 semanas consecutivas a la baja. https://bit.ly/3aam5FW

Intervozes (2018). Marco Civil da Internet. Violações ao direito de acesso universal previsto na lei. http://intervozes.org.br/arquivos/interliv012mci2018.pdf

Karisma (25 de abril de 2020). Pandemia, censura y control a la libertad de expresión en internet. https://bit.ly/3ijSoVK

Katzenbach, C. (2012). Technologies as institutions: Rethinking the Role of Technology in Media Governance Constellations. En Just, N y Puppis, M. (eds). Trends in communication policy research: new theories, methods and subjects, Intellect.

IFT (2 de abril de 2020). Exhorto a las autoridades federales, estatales y municipales para que, en el ámbito de sus atribuciones, coadyuven a la continuidad en la prestación de los servicios de telecomunicaciones y radiodifusión ante la contingencia COVID-19. https://bit.ly/3a6PeS5

IFT (20 de marzo de 2020b). Operadores de telecomunicaciones móviles ofrecerán acceso gratuito a contenidos oficiales sobre coronavirus. https://bit.ly/3ih5Olj

IFT (S/Fa). Anuario estadístico 2019. https://bit.ly/3a1VxXe

IFT (S/Fb). Cuarto informe estadístico trimestral 2019. https://bit.ly/3gxi9kR

Jenkins, H. (2006). Convergence Culture: Where old and new media collide. New York University Press.

Iglesias, F. (27 de diciembre de 2019). Argentina: una de cada diez conexiones fijas ya son por fibra óptica. Josecrettaz.com. https://bit.ly/33uK7Kq

Lara, C. (1 de mayo de 2020). La pandemia de COVID-19 y la pulsión por la vigilancia estatal. Derechos Digitales. https://bit.ly/3gzfeIw

La Nación (10 de abril de 2020). Coronavirus en la Argentina: la oposición pide que el Gobierno explique qué hará con los datos personales de la app CuidAR. https://bit.ly/2DE2EsM 
La Voz del Interior (27 de abril de 2020). ¿Funcionó el nuevo límite de reenvío en WhatsApp a una vez por chat? Los números dicen que sí. https://bit.ly/3gC01Gm

La Voz del Interior (4 de abril de 2020b) Por el Covid-19, Bolsonaro enfrenta su peor crisis. https://bit.ly/31sXDf1

Lessig, L. (2004). Free Culture. How big media uses technology and the law to lock down culture and control creativity. Penguin Press.

MacBride, S. \& alt. (1980). Many voices, one world. UNESCO, Paris.

Milan, S. \& van der Velden, L. (2016). The Alternative Epistemologies of Data Activism Digital Culture and Society, 2(2): 57-74. https://doi.org/10.14361/dcs-2016-0205

Observacom (9 de noviembre de 2018). Se "cayó" el proyecto de ley sobre responsabilidad de intermediarios en Argentina. https://bit.ly/2F4O1OR

OEA (2020). COVID-19: Los gobiernos deben promover y proteger el acceso y la libre circulación de la información durante la pandemia - Expertos internacionales. OEA. http://www. oas.org/es/cidh/expresion/showarticle.asp? artID $=1170 \& l I D=2$

OEA (2019). Declaración Conjunta del Vigésimo Aniversario: Desafios para la Libertad de Expresión en la Próxima Década. https://bit.ly/2XDpasQ

OEA (2011). Declaración conjunta sobre libertad de expresión e Internet. http://www.oas.org/es/ cidh/expresion/showarticle.asp? artID $=849 \& l I D=2$

ONU (2020). Disease pandemics and the freedom of opinion and expression. Report of the Special Rapporteur on the promotion and protection of the right to freedom of opinion and expression. https://bit.ly/2XCMs1X

ONU (2018). Consejo de Derechos Humanos. Informe del Relator Especial sobre la promoción y protección del derecho a la libertad de opinión y expresión, David Kaye. https://freedex.org/wpcontent/blogs.dir/2015/files/2018/05/G1809672.pdf

Oszlak, O. \& O’Donnell. G. (1981). Estado y políticas estatales en América Latina: hacia una estrategia de investigación. Centro de Estudios de Estado y Sociedad (CEDES), Documento G.E. CLACSO. Vol. 4, Buenos Aires. https://bit.ly/2DtERfq

Posetti, J. \& Bontcheva, K. (2020a). DISINFODEMIC: Deciphering COVID-19 disinformation. UNESCO. https://bit.ly/33B3a5D

Posetti, J. \& Bontcheva, K. (2020b).DISINFODEMIC: Dissecting responses to COVID-19 disinformation. UNESCO. https://bit.ly/3gDjBlM

Prato, A. V. y Segura, M. S. (eds.) (2018). Estado, sociedad civil y políticas culturales. Rupturas y continuidades en Argentina 2003-2017. RGC Ediciones.

R3D (25 de marzo de 2020). Creative Commons llama a reforzar el acceso abierto durante la emergencia sanitaria mundial. https://bit.ly/3ij48I6

R3D (27 de abril de 2020b). Gigantes de tecnología se suman al 'Compromiso COVID abierto'. https://bit.ly/3gE7IvM

Roca, R. (2 de abril de 2020). En tiempos de crisis todas las comunidades necesitan estar conectadas. Internet Society. https://bit.ly/3fGU1e9 
Rojas, M (17 de abril de 2020) Con geolocalización de casos de COVID-19, BCS instalará cercos sanitarios. Microsoft News. https://bit.ly/30ygqGq

RSF (2019). Monitoreo de la propiedad de los medios en Argentina. http://argentina.mom-rsf.org/ es/

Secretaría de Salud (2020). ACUERDO por el que se establecen las medidas preventivas que se deberán implementar para la mitigación y control de los riesgos para la salud que implica la enfermedad por el virus SARS-CoV2 (COVID-19). https://www.dof.gob.mx/nota_detalle. php? codigo $=5590339 \&$ fecha $=24 / 03 / 2020$

Segura, M. S. (2019) Activismo por los derechos digitales en América Latina. Pensar globalmente, actuar localmente. Revista Persona y Sociedad, 33 (2), 198-228. https:// personaysociedad.uahurtado.cl/index.php/ps/article/view/279

Segura, M. S. (2018). De la resistencia a la incidencia. Sociedad civil y derecho a la comunicación en Argentina. Ediciones UNGS.

Segura, M. S. \& S. Waisbord (2019). Between data capitalism and data activism. Television \& New Media, 20 (4), 1-8. https://doi.org/10.1177\%2F1527476419834519

Segura, M. S. \& S. Waisbord (2016). Media movements. Civil society and media policy reform in Latin America. Zedbooks.

Sorj, B. (2010). Usos, abusos y desafios de la sociedad civil en América Latina. Siglo XXI.

Telesemana (2020). Fibra en Latinoamérica: más despliegues y mejores servicios. https://bit. ly/3ijU5T6

UNESCO (2020). Declaración sobre el Covid-19: consideraciones éticas desde una perspectiva global. https://unesdoc.unesco.org/ark:/48223/pf0000373115_spa

UNESCO (2019). Tendencias mundiales en libertad de expresión y desarrollo de los medios: informe regional para América Latina y el Caribe 2017/2018. https://bit.ly/3a1UsPe

Valente, J. (16 de abril de 2020). Justiça permite corte de serviços de telecomunicações de inadimplentes. Agência Brasil. https://bit.ly/3a4QULV

Wu, T. (2003). Network neutrality, broadband discrimination. Journal of Telecommunications and High Technology Law, 1(2): 141-179. http://dx.doi.org/10.2139/ssrn.388863

Zuboff, Sh. (2019). The age of surveillance capitalism. Public Affairs: New York. 